\title{
Degradation of Structure of Magnetron Ni and Cr Nanofilms at their Heating on Air
}

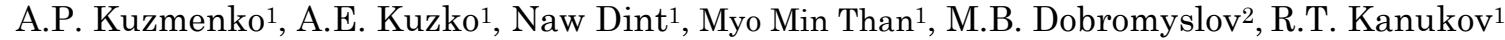 \\ 1 South-West State University, 94, 50 Let Oktyabrya st., 305040 Kursk, Russia \\ 2 Pacific National University, 136, Tikhookeanskaya st., 680035 Khabarovsk, Russia
}

(Received 25 April 2016; published online 03 October 2016)

\begin{abstract}
The present results of comprehensive researches of degradation processes for magnetron metal nanofilms of $\mathrm{Ni}$ and $\mathrm{Cr}$ when heated on air (373-1273 K) conducted by nanotechnology instruments. Temperatures of structural and phase transformations, interrelation of amplitude and phase-frequency components of ellipsometry measurements with "ferromagnetic-antiferromagnetic" for $\mathrm{NiO}$ phase transition are established
\end{abstract}

Keywords: Magnetron, Ferromagnetic-antiferromagnetic, Nanofilms, Ellipsometry.

DOI: $10.21272 /$ jnep.8(3).03007

PACS numbers: 07.60.Fs, 75.50.Cc

\section{INTRODUCTION}

$\mathrm{Cr}$ and $\mathrm{Ni}$ are widely use in the production of highresistive conductors with a reduced width of transitions on multilayered microelectronic printed- circuit boards. Substrates boards are metallized with chromium, which increases adhesion, and gold contacts are coated with nickel, which improves service life and prevents from copper migration [1]. After heating of a chromium film to $773 \mathrm{~K}$, the crystalline randomly oriented structures of $\mathrm{Cr}_{2} \mathrm{O}_{3}$ [2] are found, and heating from 973 to $1273 \mathrm{~K}$ leads to coagulation processes [3]. The surface of nickel oxide $\mathrm{NiO}$ is formed after heating of a nickel film over $423 \mathrm{~K}$ [4].

\section{INVESTIGATION RESULTS}

Structural changes of magnetron films from $\mathrm{Cr}$ and $\mathrm{Ni}$ when heated on air, according to atomic force microscopy (AFM), had a features of distinct number are shown in Fig. 1. The sizes of chromium nanoparticles are practically did not change when heated to $673 \mathrm{~K}$, had spherical shape with a minimum size of $30 \mathrm{~nm}$ (Fig. 1, a and b). At the temperature increased, the forming of nanoparticles size of the film were becoming larger and the formation of clusters up to $125 \mathrm{~nm}$ at $T=1073 \mathrm{~K}$ was noted (Fig. 1, b). Beginning with $1173 \mathrm{~K}$, the structure of $\mathrm{Cr}$ films, according to AFM, became clearly disordered in character.

The nanoparticles size of nickel, according to AFM, at room temperature were $\sim 30 \mathrm{~nm}$. When heated in the range of $373-673 \mathrm{~K}$, the clusterization to the sizes $100 \mathrm{~nm}$ with an oval form was observed (Fig. 1, c). Further when heated up to $1273 \mathrm{~K}$ the form of particles became acute angled, crystals with sizes up to $1 \mu \mathrm{m}$ were formed in (Fig. 1, d).

In the range of $773-1073 \mathrm{~K}$, the temperature dependence of the nanoparticle sizes $d(T)$ of $\mathrm{Cr}$ became nonlinear in character; the sizes of nanoparticles increased from 30 to $125 \mathrm{~nm}$. As distinct from the presented in Fig. 1 topographical images, the changes on it of the lateral amplitude

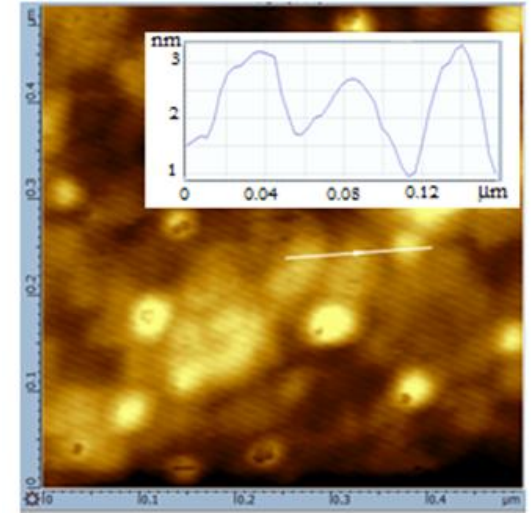

a

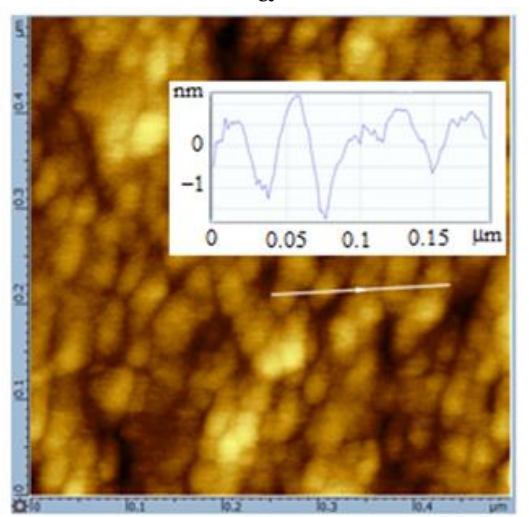

$\mathrm{b}$

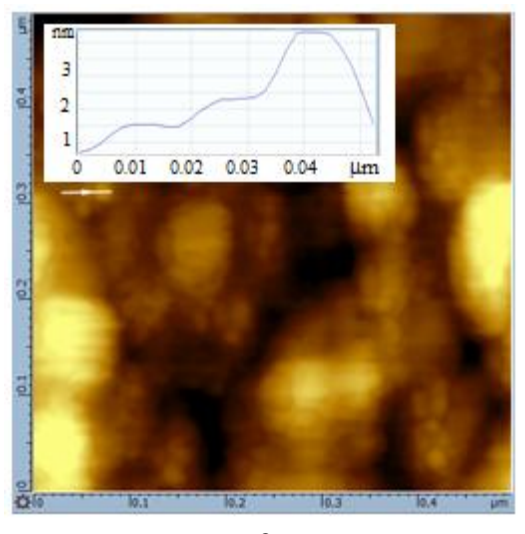

c 


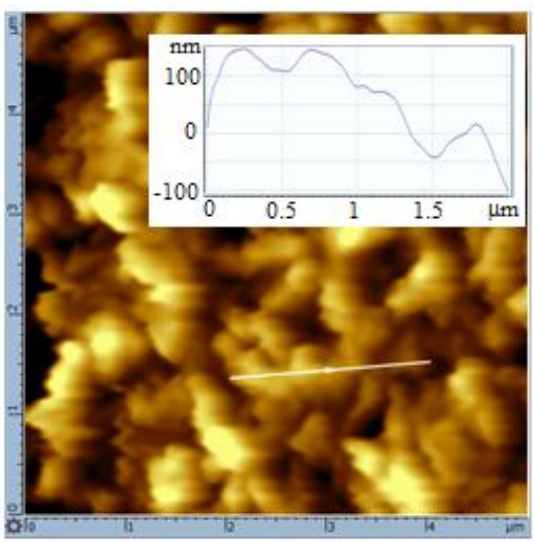

d

Fig. 1 - Atomic-force images of the structure of magnetron nanofilms on polycrystalline glass from $\mathrm{Cr}(\mathrm{a}, \mathrm{b})$ and $\mathrm{Ni}(\mathrm{c}$, d) at a temperature: $\mathrm{a}-373 \mathrm{~K} ; \mathrm{b}-673 \mathrm{~K} ; \mathrm{c}-378 \mathrm{~K}$; $\mathrm{d}-873 \mathrm{~K}$

and a phase established borders between separate structural elements more distinctly. So, at $T=1073 \mathrm{~K}$ the sizes of separate nanoparticles increased up to more than $100 \mathrm{~nm}$ and also their form changed from typical at lower temperatures - oval to angulated, but with a clear boundary.

AFM-images of a magnetron coating from Ni show single-phase surface and sphere-like shape of the constituent nanoparticles which a minimum size of $30 \mathrm{~nm}$. Beginning with $373 \mathrm{~K}$, in the same contrast AFM-images demonstrate the emergence of two phases. However, the form of the particles forming the surface structure remained spherical. At $773 \mathrm{~K}$, steplike structures began to arise and angularity of the shape of separate nanoparticles (Fig. 1, d) manifested itself, whose development increased up to the largest studied temperature $1273 \mathrm{~K}$. In the temperature range of $973-1273 \mathrm{~K} d(T)$ became nonlinear in character. The arising restructuring was followed by growth of the sizes and change of the form, the formation of crystallites. At $973 \mathrm{~K}$ the melting of particles began.

Changes of the sizes and surface structure of magnetron films from $\mathrm{Cr}$ and $\mathrm{Ni}$ are investigated also on scanning electron microscopy SEM-images given in Fig. 2. According to SEM-images, the chromium film at all temperatures lower than $1173 \mathrm{~K}$ is regular in structure and is formed by particles whose sizes vary from 50 to $200 \mathrm{~nm}$. Different changes of structure were observed in nickel films when heated. So, when heated up to $673 \mathrm{~K}$, the structure did not undergo changes and the sizes of particles were within $100 \mathrm{~nm}$ (Fig. 2, c). Beginning with 673 to $873 \mathrm{~K}$, the sizes of acute-angled crystallites were observed to become larger by several times (Fig. 2, d); however, at further heating their form became blurred.

The changes of spectral ellipsometry (SE) characteristics of the surface of magnetron nanofilms of $\mathrm{Cr}$ and $\mathrm{Ni}$ arising when heated in the muffle furnace in the air atmosphere are analyzed. The initial one to one correspondence between the coefficient of reflection [5]:

$$
\rho=R_{\mathrm{p}} / R_{\mathrm{s}}=\operatorname{tg} \psi \exp (i \Delta)
$$
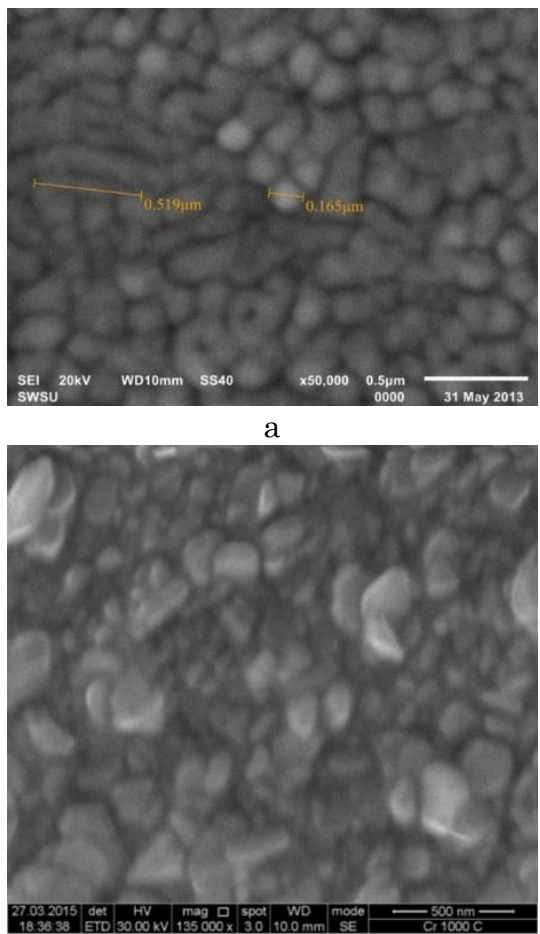

b
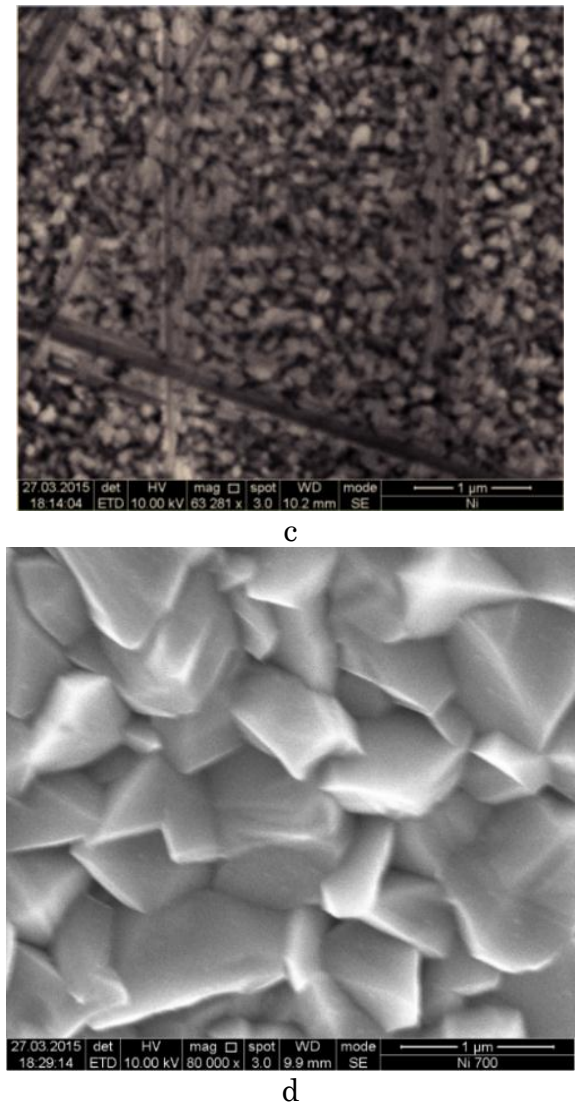

Fig. 2 - SEM-images of the surface of magnetron films $\mathrm{Cr}(\mathrm{a}, \mathrm{b})$ and $\mathrm{Ni}$ (c, d) a - $298 \mathrm{~K}$; b - $1273 \mathrm{~K}$; c-298 K; $\mathrm{d}-973 \mathrm{~K}$

for all ellipsometry angles $(\cos \Delta(\lambda)$ and $\operatorname{tg} \psi(\lambda))$ and reflection coefficients $\left(R_{\mathrm{p}}\right.$ and $\left.R_{\mathrm{S}}\right)$ with orthogonal polarization was determined by this fact.

Both for $\mathrm{Cr}$ and $\mathrm{Ni}$ changes in polarizing characteristics $\Delta(\lambda)$ and tg $\psi(\lambda)$ are found. For example, 
for $\mathrm{Cr}$ the changes in tg $\psi(\lambda)$ were recorded beginning with $473 \mathrm{~K}$ at a wavelength of $450 \mathrm{~nm}$, which were remained constant up to $973 \mathrm{~K}$ when the jump of $\Delta(\lambda)$ occurred, which disappeared with consecutive heating.

By using the dispersive dependence of phase $\varphi(\lambda)=\operatorname{arctg} \quad(\operatorname{Im} \rho(\lambda) / \operatorname{Re} \rho(\lambda)), \quad$ the wavelength and temperature ranges were determined. So, for $\mathrm{Cr}$ only one exceptional point at $\lambda=450 \mathrm{~nm}$ in a temperature range 473-973 K was found. Phase changes for Ni were of more difficult character. In the range from $T_{\mathrm{R}}$ to $573 \mathrm{~K}$ switching of $\varphi(\lambda)$ occurred at $\lambda=320 \mathrm{~nm}$, which, probably, corresponded to a plasmon resonance. At $673 \mathrm{~K}$ in the range $\lambda=280-600 \mathrm{~nm}, \varphi(\lambda)$ was positive, and then at $773 \mathrm{~K}$ overturned and the point of switching was shifted into the long- wave area.

In the dependence of an amplitude component $|\rho(\lambda)|=\left((\operatorname{Re})^{2}+(\operatorname{Im} \rho)^{2}\right)^{1 / 2}$ just at $\lambda=450 \mathrm{~nm}$ a jump was observed when $\mathrm{Cr}$ film was heated up to $970 \mathrm{~K}$. At temperatures higher than $1073 \mathrm{~K},|\rho(\lambda)|$ for $\lambda$ from 270 to $600 \mathrm{~nm}$ monotonously decreased, and then it increased, which was indicative of the structure of the film surface intact. In Ni films, to $573 \mathrm{~K}|\rho(\lambda)|$ remained constant in all spectral range. At $673 \mathrm{~K}$ $|\rho(\lambda)|$ monotonously increased to $600 \mathrm{~nm}$, and then it decreased. At further temperature, increase $|\rho(\lambda)|$ remained invariable, but decreased in value, which indicated the dispersion growth owing to disordering of the film surface.
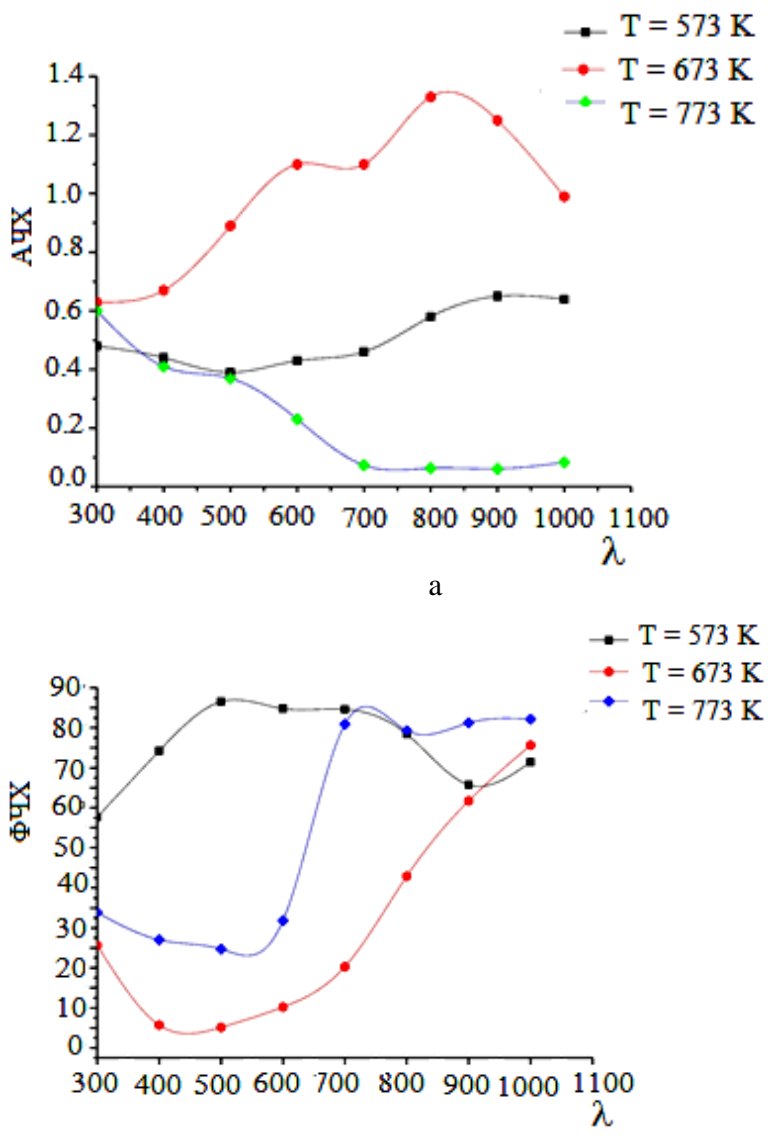

$\mathrm{b}$

Fig. 3-Temperature changes in spectral ellipsometry characteristics in a Ni film: a - AFC; b- PFC

Double growth of AFC for SE at the Curie temperature in the visible range was observed, up to
$800 \mathrm{~nm}$, to the border of the near IR-area. At the same time, PFC at the same lengths was close to zero, whereas at $573 \mathrm{~K} \varphi(\lambda)$ changed in an antiphase, and after $T_{\mathrm{K}}($ at $773 \mathrm{~K}$ ) its change became in-phase. Thus, according to $\mathrm{SE}$, the second-order ferromagnet-to-antiferromagnet phase transition in magnetron nanofilms of $\mathrm{Ni}$ at their heating to the Neel temperature $T_{\mathrm{H}}$ $(520 \mathrm{~K})$ was recorded.

Structural research of morphology of the studied surfaces at the same heating temperatures was supported with evidence of changes in their chemical structure. All reorganizations of phase structure arising at all stages at all studied heating temperatures are shown in Fig. 4. It is possible to stress that already prior to the beginning of heating $\mathrm{NiO}_{2}-2 \theta=46^{\circ}$ traces are found:

$$
\mathrm{Ni}+\mathrm{O}_{2} \rightarrow \mathrm{NiO}_{2}
$$

At the same temperature, in X-ray spectrum a number of lines appeared corresponding to a glass ceramic substrate, for example: $\mathrm{TiO}_{2} 2 \theta=44,54,63$, $74^{\circ} ; \mathrm{MgAl}_{2} \mathrm{O}_{5} 2 \theta=49^{\circ}$. The analysis results of the temperature changes of intensity of the most significant lines both for $\mathrm{Ni}$ and its oxides are presented in Fig. 4. An increase in the intensity of the reflexes corresponding to $\mathrm{Ni}$ and its oxides when heated is found. After heating of the coating to $573 \mathrm{~K}$, according to X-ray phase analysis, $\mathrm{Ni}$ began to be oxidized [4]

$$
\mathrm{Ni}+1 / 2 \mathrm{O}_{2} \rightarrow 2 \mathrm{NiO}
$$

This reaction is corroborated by the changes that were noted in $[6,7]$

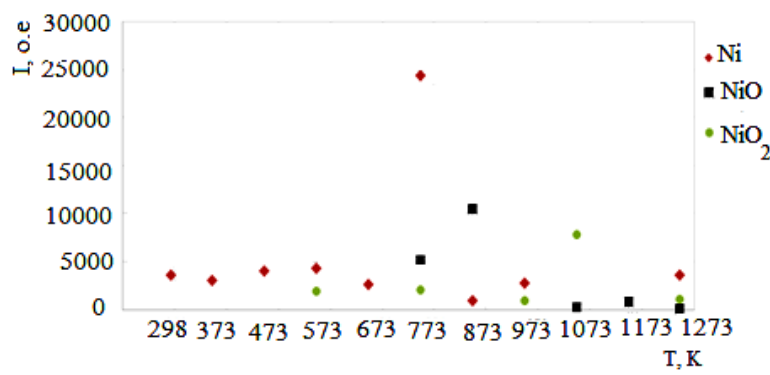

Fig. 4-Temperature dependence of the intensity of the most significant X-ray reflexes for a magnetron Ni nanofilm

The changes in the intensity of the most characteristic lines in Raman scattering spectrum arising at heating are presented in Fig. 5, which confirms the possible oxidizing reactions (2) and (3).

\section{CONCLUSION}

The magnetron nanofilms of $\mathrm{Ni}$ and $\mathrm{Cr}$ widely used in electronics have been investigated. The morphological and chemical structural changes of their surfaces arising at their heating on air (up to $1273 \mathrm{~K}$ ) were obtained by methods of probe and raster microscopy, Raman light scattering, the X-ray phase analysis and the spectral ellipsometry. The temperature 


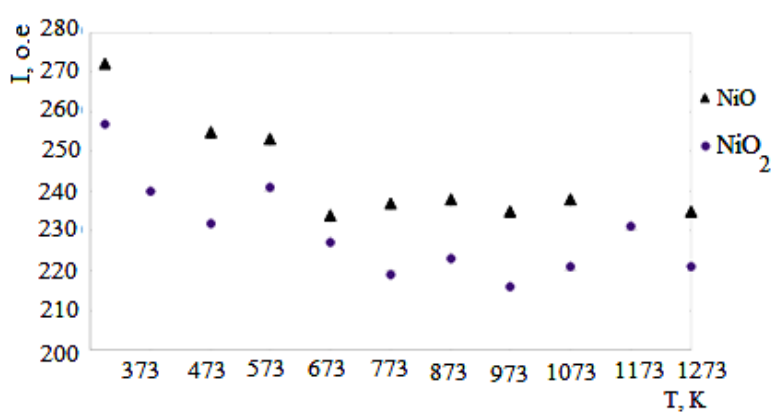

Fig. 5-Temperature dependence of the intensity of separate lines in the Raman spectrum for nickel magnetron films

\section{REFERENCES}

1. Wei-Xi Zhou, Yan Shen, Er-Tao Hu, Opt. Express 20 No 27, 28953 (2012)

2. T. Ivanova, K. Gesheva, A. Cziraki, J. Phys.: Conference Series 113, 012030 (2008).

3. U.V. Naidich, I.I. Gab, B.D. Kostyuk, Reports of the National Academy of Sciences of Ukraine No 5, 97 (2007).

4. A. Ionescu, S. Holmes, C.H.W. Barnes, J. Vac. Sci. of the first-order structural phase transition as a partial melt of some oxides is determined, and according to phase- and amplitude-frequency ellipsometry components at a temperature which coincided with the Curie temperature for $\mathrm{Ni}$, the second-order ferromagnet to antiferromagnet phase transition in a nickel nanofilm is confirmed.

Technol. B 32 No 5, 051808 (2014)

5. H.Y. Joo, H.J. Kim, S.J. Kim, Thin Solid Films 368, 67 (2000).

6. P.R. Dahoo., T. Hamon, B. Negulescu, Appl. Phys. A $\mathbf{7 9}$ 1439 (2004).

7. I. Dhanya, B. Sasi, J. Coat. 2013, ID981515 (2013). 